\title{
Talent measurement: A holistic model and routes forward
}

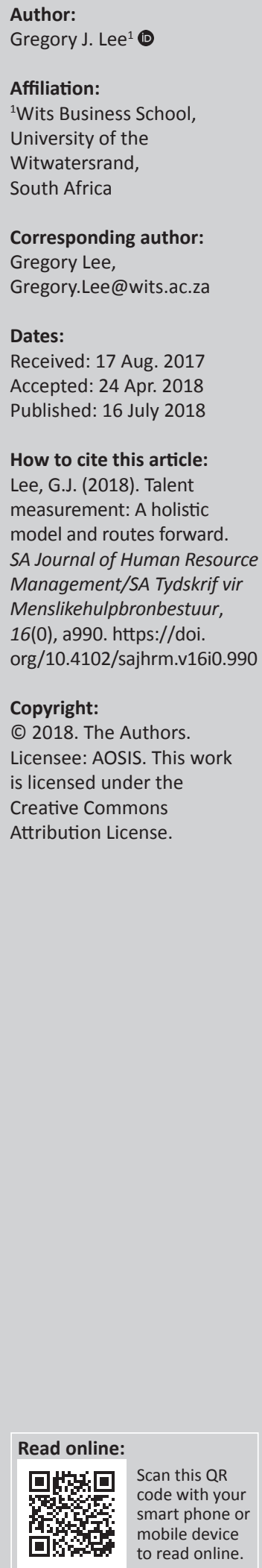

Orientation: Talent measurement is a critical input to talent management (TM). Involving the application of measurement methodologies in order to determine the current and longer-term potential, competencies and contribution of employees and their roles, talent measurement is a growing field of interest in human resources.

Research purpose: This article reviews and integrates the practice of talent measurement, including developing a model of talent measurement, rooting the practice in theory and suggesting several relatively unexplored aspects of talent measurement that may have potential for improvement or controversy.

Motivation for the study: Talent measurement has not been adequately discussed and critiqued.

Research approach/design and method: A theory review and development approach is taken in this article.

Main findings: A holistic model for talent measurement is presented, including elements that have not received much prior attention such as theoretical foundations, the practicalities of including a role element, the advisability of using talent pools, the question of whether talent measures or status should be revealed to employees, the integration of talent pools with diversity or transformation imperatives, and others.

Practical/managerial implications: Managers who employ TM should benefit from this review and set of challenges regarding the practice of talent measurement.

Contribution/value-add: Although TM has been extensively discussed, the specific measurement options involved have been less well examined. Development of a holistic model and identification of outstanding controversies within it provide value to practitioners and to the evolution of TM.

\section{Introduction}

The notions of talent and talent management (TM) have become prevalent thrusts within modern human capital management. Talent management generally requires organisations to employ formalised talent measurement methodologies, which can be defined as the application of measurement methodologies in order to determine the current and longer-term potential, competencies and contribution of employees (Boudreau \& Ramstad, 2005a, 2005b; Nijs, GallardoGallardo, Dries, \& Sels, 2014). Such measurement exercises can become critical inputs to TM, as evaluation of individuals or identification of appropriate segments of the workforce guides the decisions required in such programmes.

Talent measurement is a growing field of interest in the human resources field, given its importance to critical input to TM. However, little systematic writing or empirical research exists on talent measurement. Specifically, the practice has not been rooted in management theory, nor has it been seen or modelled as a whole system, and several areas of uncertainty remain. This article discusses the practice of talent measurement in general and develops a comprehensive model of talent measurement that is capable of acting as a guide for practitioners as well as a theory development template. This model is a unique contribution and contains within it several substantive contributions as well, such as a discussion of the theoretical foundations of talent measurement (which has been lacking) as well as discussions on many underdeveloped possibilities such as role and team foci, systematic methodological options and integration of talent measurement with other imperatives such as transformation.

\section{A review of talent concepts}

This section defines key terms, discusses talent measurement in broad terms, locates the practice of talent measurement within a theoretical framework and reviews the nine-box grid as an example. 


\section{Defining talent and talent management}

It is helpful to begin with some related definitions to clarify key concepts. For the purpose of this article, the following definitions will apply.

\section{Defining talent}

Talent has become a particularly fluid and contested concept (e.g. Gallardo-Gallardo, Dries, \& González-Cruz, 2013; Iles, Chuai, \& Preece, 2010; Lewis \& Heckman, 2006; Tansley, 2011). Ultimately this article will employ the wording of Nijs et al. (2014), which may provide the most systematically useful and comprehensive definition:

Talent refers to systematically developed innate abilities of individuals that are deployed in activities they like, find important, and in which they want to invest energy. It enables individuals to perform excellently in one or more domains of human functioning, operationalized as performing better than other individuals of the same age or experience, or as performing consistently at their personal best'. (p. 182)

Although there are many elements of talent, practically, the concept is treated on a continuum. On one extreme, the exclusive approach considers talent as one or more elite subsets ('talent pools') of employees whose combination of human capital, attitudinal elements (such as engagement) and behaviour entails a high potential of current or future value and productivity to an organisation, in the context of both the individual's role, identity and profession and the organisation's specific requirements (CIPD, 2009; Iles et al., 2010). On the other extreme, an 'inclusive' approach considers all employees as talent (notably based on the notion that it is systems and interactions of people that create real long-term sustainable competitiveness, see, for instance, Iles, 2008; Iles \& Preece, 2006; Swailes, Downes, \& Orr, 2014). A hybrid approach seems to be to segment all employees into talent pools, with some pools being identified as more critical or specialised but with a general ethos of good human resource management (HRM) applied to all (e.g. Boudreau, 2013; Ulrich \& Smallwood, 2012).

The definition and practical treatment of talent will fundamentally affect both measurement, as discussed later, and management. In all cases, however, it is a commonly held belief in modern day HRM that talent forms a core sustained competitive advantage for firms.

\section{Defining talent management}

Talent management then refers to:

[...] the identification, development, engagement/retention and deployment of those employees who are particularly valuable to an organization - either in view of their 'high potential' for the future or because they are fulfilling business/operation-critical roles. (Iles, 2008: 215; CIPD, 2016)

and similarly (Collings \& Mellahi, 2009):

[...] activities and processes that involve the systematic identification of key positions which differentially contribute to the organisation's sustainable competitive advantage, the development of a talent pool of high potential and highperforming incumbents to fill these roles, and the development of a differentiated architecture to facilitate filling these positions with competent incumbents and to ensure their continued commitment to the organisation. (p. 305)

Talent management therefore entails targeted human resource policies designed to increase and improve the talent pool. Within the exclusive view of talent, a talent pool is often first identified through talent measurement, as discussed next, and specific HRM interventions targeted at them, such as enhanced learning opportunities, retention bonuses and the like (Iles et al., 2010). Within the inclusive approach, the task becomes either to identify each individual's current capabilities and opportunities for growth and maximise these or to optimise the social capital inherent within organisational structures and systems that over time produces and nurtures talent, with organisational culture and leadership being core examples (Iles et al., 2010).

It is within the context and requirements of TM that talent measurement has its place as an analytical methodology, as discussed next.

\section{An overview and model of talent measurement}

Having defined talent and TM, this section overviews the use and practice of talent measurement.

Talent measurement is defined broadly here as the practice of applying specific measurement methodologies to employees in order to determine their potential current and longer-term competencies and contribution to the organisation, for the purposes of facilitating talent management.

Despite the fact that talent measurement has implicitly or explicitly always been a part of TM, little systematic writing exists to develop the measurement itself as a focus and field. Indeed, the measurement part of TM has arisen unevenly, mostly from practice exemplars like the General Electric nine-box grid, which will be discussed briefly later. Theoretical foundations and drivers have not been developed, and aside from recent contributions (notably Nijs et al., 2014) little systematic writing exists on the concept.

Accordingly, this article seeks to add to the literature reviewing and conceptualising talent measurement. It does so firstly by presenting a conceptual framework for the elements involved in a talent measurement and execution system, as shown in Figure 1.

As can be seen, the model suggested in Figure 1 arises from certain theoretically derived drivers, something that has lacked systematic discussion in TM literature. Then, measurement design elements must be chosen, with a variety of options available. A point discussed below is that not all of these are always considered in contemporary 


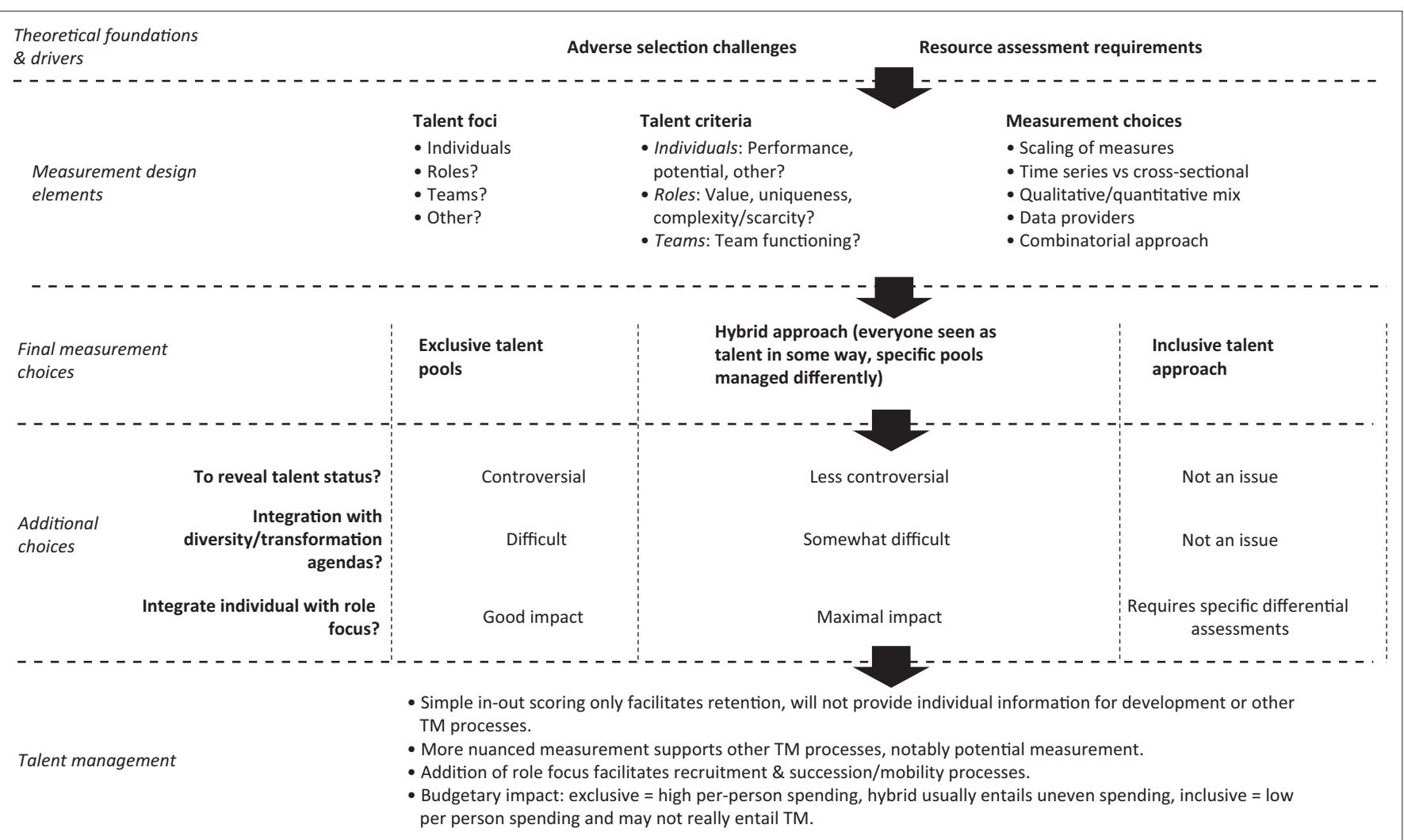

FIGURE 1: A framework of the talent measurement process and elements.

systems. Final system design can broadly be classified as exclusive, hybrid or inclusive. Further issues could be explored, which again are often not considered adequately and therefore form areas of controversy or opportunity. This article adds some unique perspectives on these additional areas. Finally, the system chosen must facilitate TM, which according to this article is not always optimally considered. The article proceeds by considering each of the areas shown in Figure 1.

\section{Element 1: Theoretical foundations of talent measurement}

As noted in the Introduction, although TM has to some extent been given theoretical foundations, the practice of talent measurement specifically has yet to be rooted in management theory. This section suggests some theoretical foundations.

As for TM, resource-based theory as applied within strategic human resource theory provides one theoretical basis for talent measurement. The broadly defined resourcebased view (Barney, 1991; Wernerfelt, 1984) proposes that firms gain and sustain competitive advantage through the cultivation of resources that are valuable, rare and hard to imitate or substitute. Arguments have been made for both human capital itself and systems of HRM to fulfil these conditions for competitive resources (Barney \& Wright, 1998; Boxall, 1996; Lado \& Wilson, 1994; Wright, Dunford, \& Snell, 2001; Wright, McMahan, \& McWilliams, 1994). These contributions argue convincingly that features of human capital and HRM systems such as the fundamental value of human competence, complex and causally ambiguous social and team systems, the influence of firm history and culture on the use of human capital, the role of organisational learning and other elements create the potential for sustained competitive advantage. However, an important set of evolutions in the application of resourcebased theory, notably the 'HR architecture' view, moved beyond a simplistic perspective of equal contribution across a firm's human capital (Kang, Morris, \& Snell, 2007; Lepak \& Snell, 1999, 2002; Liu, Lepak, Takeuchi, \& Sims, 2003; Martin, 2009; Palthe \& Kossek, 2003; also see Kulkarni \& Ramamoorthy, 2005). This type of view argues for differential value and uniqueness between human capital resource types and calls, therefore, for concomitant differences in employment mode, relationship and HR configurations. It is within this framework that talent measurement has its first theoretical location, as a critical tool in the organisation's ability to locate value and uniqueness.

Furthermore, adverse selection theory provides a second theoretical foundation for the practice of talent measurement (Akerlof, 1976; Wright \& McMahan, 1992). This branch of information economics focuses on the transactional problems of asymmetric information, which in the context of employment relationships refers to employers' challenges of accurately knowing and acting on the productive potential of employees, applicants, or hiring prospects. In the context of a current employee pool, one particular challenge includes accurately assessing employees for future contribution, especially where promotion or alternate future roles is a key consideration. In such longer-term considerations, current 
employee performance or expressed desire for advancement may not be sufficient or desirable as a sole indicator - for instance, the 'rat race' conceptions of adverse selection (e.g. Akerlof, 1976; Landers, Rebitzer, \& Taylor, 1996) suggest theoretically and empirically that promotion races based exclusively on output may lead to inefficiently high levels of competition. However, the more that a current employer firm can screen its employees for hard-to-observe future potential and capability, the more that it potentially gains advantages over labour market competitors and is able to retain and utilise such talent (e.g. Greenwald, 1986; Kahn, 2013). In addition, attraction-selection-attrition theory (Schneider, 1987) may be used to suggest that policies such as talent assessment criteria (e.g. definitions of what the firm sees talent in an exclusionary context and methodologies for assessing it) may act as powerful signals (King, 2016), enabling not only systematic recruitment and selection of such individuals over time but also retention of such individuals and turnover of individuals who fit such 'moulds' to a lesser extent. Individuals with less talent ' $f i t$ ' are thereby not only systematically weeded out of the workforce, but may even self-select out of the application stage to the mutual benefit of both the individual and the firm, given that poor person-organisation fit is generally an undesirable outcome (Kristof-Brown, Zimmerman, \& Johnson, 2005). Screening, signalling and self-selection are ultimately seen as solutions for the adverse selection problem and may be facilitated by talent measurement systems.

\section{Element 2: Choices of measurement design elements}

As noted in Figure 1, several design elements can be considered in a talent measurement system, including the measurement foci, criteria and methodological elements.

\section{Measurement foci}

As noted in Figure 1, a fundamental set of methodological choices involves the foci of analysis. A primary focus on the individual almost always accords with the core definition of talent and focus of TM and would seem to be a given staple for any TM programme. However, nascent literature may suggest additional foci that are certainly not common to contemporary TM practice but that may add enormous value. This article will briefly discuss roles and teams as two options.

\section{Explicitly including a role focus in measurement}

A point that has often been made in talent and TM definitions but that has not fully penetrated measurement practices is that the role currently fulfilled by individuals may also impact their treatment in TM, or in fact that the role may be the foremost issue of concern (Boudreau \& Ramstad, 2005b; Collings \& Mellahi, 2009; Huselid, Beatty, \& Becker, 2005; Iles et al., 2010; Martin, 2009; Minbaeva \& Collings, 2013).

This point has been surfaced explicitly by Huselid et al. (2005), who argue convincingly that organisations should first identify segments of roles (in their conception, these would be ' $A$ ', 'B' and ' $C$ ' roles hierarchically defined by importance), and then assess and optimise individual and resource allocations between these roles, favouring critical roles, as well as prioritise acquisition for vacancies in critical roles, a position echoed and expanded by others (Boudreau \& Ramstad, 2005b; Collings \& Mellahi, 2009). Similarly, Iles et al. (2010) distinguish four types of TM by combinations of exclusive/inclusive and position/ person foci, therefore explicitly incorporating the role focus. Similar sentiments are implicit elsewhere. For instance, in the definition of TM explored earlier, TM was extended to 'those employees who are particularly valuable to an organization - either in view of their "high potential" for the future or because they are fulfilling business/operation-critical roles' (CIPD, 2016; Iles, 2008). Similarly, Collings and Mellahi (2009) define strategic TM as:

[...] activities and processes that involve the systematic identification of key positions which differentially contribute to the organisation's sustainable competitive advantage, the development of a talent pool of high potential and high-performing incumbents to fill these roles, and the development of a differentiated architecture to facilitate filling these positions with competent incumbents and to ensure their continued commitment to the organisation. (p. 305)

The inclusion of a role element also accords with theory. As discussed earlier in the 'Element 1: Theoretical foundations of talent measurement', resource-based theory would define critical roles as those high in value, rarity, non-imitability and non-substitutability. Lepak and Snell (1999) apply such concepts to the HR architecture, which delineates roles not in fact individuals, and similar approaches have been used by others since in the TM literature (e.g. Martin, 2009).

However, despite recognition that the role may have a profound influence on TM, there is practically no formal guidance or debate on how practically to include such considerations into a measurement system. Clarifying the ways in which roles could be assessed and integrated with individual talent measurement may be a substantive possibility for future elaboration and improvement of talent measurement systems. More discussion on this point follows below under measurement criteria and methods.

\section{Including a team focus}

A team focus could, perhaps, also form part of some talent measurement systems. On one extreme, teams could form a primary focus, for example in project management or research and development environments. In such cases, the synergies within teams may even lead to an abandonment of individual focus and a development of systems seeking to identify and nurture high-talent teams, even where individual contributions to the teams may vary (again, it may be a delicate and complex interdependence that enables the team to work). Another possibility could consider individuals within the context of teams. Further discussion on this is presented below when considering measurement criteria. 


\section{Talent measurement criteria}

This element considers which criteria should be used when assessing talent. It is not unusual for multiple criteria to enter into the measurement of talent, whether explicitly or implicitly considered.

\section{Criteria for individual talent assessment: Performance, potential and beyond}

The two elements most commonly employed as criteria in talent measurement are performance and potential.

The measurement of performance, although perennially problematic, is a well-known concept for managers. Performance appraisals are often used, although the methodological section next discusses various options in this regard.

The measurement of potential, on the other hand, is less traditional. Various suggestions have been made, such as the following question banks (e.g. McCarthy, 2009):

- Could the employee perform at a higher level, in a different position or take on increased responsibilities in the short term (consider the person's ability only, not whether there is a position available to support this growth)?

- Can the employee perform two levels above his or her current position in the medium term?

- Is the organisation likely to value growth of the skills and competencies of this employee over the next several years?

- Could the employee learn the additional skills and competencies he or she needs to be able to perform at a higher or different level?

- Does the employee demonstrate leadership ability by showing initiative and vision, delivering on promised results, communicating effectively and taking appropriate risks?

- Does the employee demonstrate an ability to comfortably interact with people at a higher level or in different areas?

- Does the employee demonstrate comfort with a broader company perspective than his or her job currently requires?

- Does the employee demonstrate flexibility and motivation to move into a job that might be different than any that currently exists?

- Does the employee welcome opportunities for learning and development?

- When would this employee be ready for a promotion?

While performance and potential are perhaps the leading considerations used in talent measurement, there may be others that may be considered, some of which are underresearched. Perhaps the most systematic suggestions regarding the domains of talent measurement can be found in the work of Nijs et al. (2014), who noted that in addition to performance and potential other elements can be measured, such as innate ability (notably through psychometric tests), developmental ability and trajectory (which in addition to performance and potential may include assessments of past education and experience), motivation (through selfassessment tools and self-reflection exercises), interests (assessed as for motivation), interpersonal excellence (typically employing identification of elite upper percentiles of employees) or intrapersonal excellence in which the individual is benchmarked against his or her own personal benchmarks (e.g. through trajectories of personal performance over time, with an emphasis on improvement). An anonymous reviewer noted that many of these may be seen as elements or elaborations on performance (e.g. inter- or intra-personal excellence) and potential (e.g. innate ability), although some - like motivation - may stand alone, as argued by Ulrich and Smallwood (2012).

Age may be another consideration, with older employees who are near mandatory retirement sometimes downgraded in potential merely because time to contribute is short. As contended by an anonymous referee:

[...] typically these criteria normally manifest in the intersubjective conversation and agreement of the talent board/ forum and in alignment with the organisation's workforce plan, rather than using them as baseline selection data.

However, firms may wish to create a 'mentor' talent pool of more experienced employees, which is given time, mandate and tools to engage in extensive mentoring.

In countries where legislative and social contexts dictate a high premium on the attraction, development and retention of specific types of employees (usually based on race, gender and considerations such as disability), these demographics may enter into the value attribution placed on employees and therefore the talent measurement system. This issue is discussed further below.

In brief, there may be a variety of added aspects of the individual which could be employed to score talent. Having said this, clearly too many aspects could add confusion and difficulty to the measurement system. Therefore, a balance would have to be achieved.

\section{Measurement criteria for roles}

Measurement criteria for assessing roles is another area, should TM professionals heed the call of Huselid et al. (2005) to, in fact, make this a primary concern. Huselid et al. suggest segmenting roles into ordinal (A, B and C) levels; however, they provide no concrete criteria for doing so. Perhaps the leading suggestion is the 'HR architecture' approach of Lepak and Snell (1999), in which roles are differentiated by value and uniqueness. However, even here little explicit guidance exists on exactly what is the best ways to score these elements, and the concept of uniqueness is arguably one with which managers may struggle. Existing job evaluation systems could aid in this process, the literature for which has developed good measures for role complexity, level of responsibility, and/or scarcity. Ultimately, choices and 
combinations of such criteria may add value not only to the talent measurement landscape but also notably to its usefulness in TM.

\section{Measurement criteria for teams}

Like individuals, team performance would seem to be an important criterion where teams are to be considered as a TM focus. In addition, however, teamwork itself could form a measure, as could other aspects such as team demography (for instance, team age, gender and race profiles where these facilitate other imperatives such as forward-looking diversity or innovation philosophies).

\section{Measurement methodology}

In addition to underlying criteria, there exist a variety of methodological elements from which to choose, including scaling, time series versus cross-sectional considerations, mix of quantitative versus qualitative assessment, and combinatorial methodology in the case of multiple criteria.

\section{Scaling choices}

Scaling choices must be made both at the criteria level and at the final talent assessment level if talent pooling is used. As usual for data analysis, basic choices are categorical, ordinal, interval or ratio scaling. Choices made at this stage will fundamentally affect the types of outcomes that can be achieved.

The simplest methodology involves simple in-out decisions regarding membership in certain talent pools (which is also the implied system where a certain percentage of employee groups or departments are identified for talent status, a relatively common approach). Such decisions implicitly still employ one or more of the criteria such as performance and potential, but with a binary measurement outcome. In/out decisions may facilitate exclusive TM, in which one outcome is to isolate one or more specific pools of 'top talent' to which specific TM strategies are applied, such as retention incentives and additional longer-term development opportunities. In the hybrid system, too, the choice to create some pools while still treating all employees as talent may employ such a simplistic system. The actual criteria involved in such binary scaling may still involve explicit or implicit attention to the aforementioned issues such as performance or potential. In-out decisions do not work for inclusive TM which implicitly treats everyone as 'in' talent (Nijs et al., 2014), and lack information for later management of talent; their use is accordingly debatable although they are used.

Organisations requiring more complexity might choose to measure criteria dimensions along continuous or ordinal measurement scales and perhaps even as the outcome of multi-item scales, ultimately using some combinatory system to adjudicate talent status. As a concrete example, certainly the most written about and seemingly the most practiced exemplar of talent measurement systems is the nine-box grid (Silzer \& Church, 2009), pioneered by General Electric in the

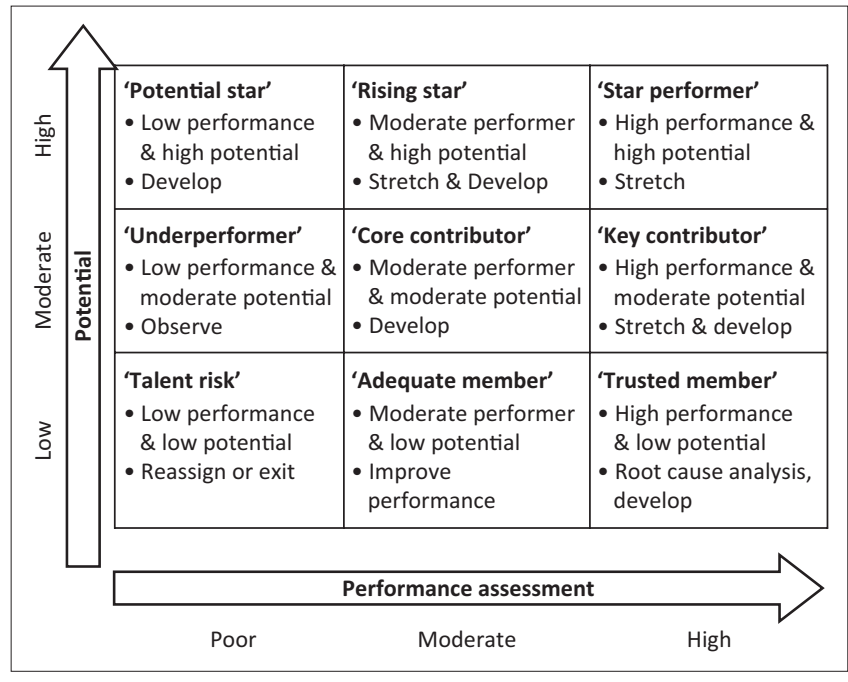

Source: Caruso, K. (2012, April 12). Development at the Top - Use the 9 Box to Develop Talen in Succession Planning. Via People Discover the Talent Within. Retrieved from http://web. viapeople.com/viaPeople-blog/bid/81566/Development-at-the-Top-Use-the-9-Box-toDevelop-Talent-in-Succession-Planning

FIGURE 2: A version of the General Electric nine-box talent measurement grid.

1970s. In this system, employees are rated on performance and potential and placed into categories. Figure 2 depicts one version of the nine-box system. These elements are discussed further below.

\section{A few variations on this grid currently exist.}

The nine-box grid is not necessarily a set methodology, as organisations could certainly tailor it to their own requirement. However, as shown in Figure 2, it is commonly presented as the result of two 3-level ordinal attributions along the performance and potential dimensions ('low', 'moderate' and 'high' for potential, and 'poor', 'moderate' and 'high' for performance). The measurement methodology is therefore explicitly categorical with ordinal inputs.

In role scoring, another prominent ordinal choice is that of Huselid et al. (2005), who, as discussed earlier, suggest a simple three-level ranking of roles.

Other options of course exist. Continuous data scoring systems can be used, although their use is far less documented than the grid-type approach. An example of continuous scaling can be to use continuous performance scores and some form of continuous potential index and then combine these into an overall index. However, one question with continuous outcome measures is how and whether they facilitate talent pools. In such cases, cut-points would be needed. For instance, as noted previously, analysts may utilise a certain percentage of the most highly rated employees, perhaps with discretionary, qualitative elements to determination of the final choices (as discussed later). One advantage of such systems is that the more metric the scale, the more information is created for subsequent TM, as discussed below.

\section{Time series versus cross-sectional considerations}

Many talent measurement systems employ only recent, cross-sectional data for assessment. This approach may make 
sense in certain contexts; however, the more data that are gathered and employed over time, the better and more complete the measure of the employees. One example of this, noted by an anonymous reviewer, is a refinement to the use of performance appraisals, namely, aggregating multiple performance appraisals into 'performance tendency' scores to get a longer-term sense of the employee.

One possibility not well mentioned in the literature is to use trajectories of scores instead of averages. For instance, especially within lower level developmental talent, employees showing exceptional trajectories of learning off even a low base may be identified as talent. In this approach, averages do not serve well; instead, slope-type analyses at the individual-level, for example, achieved through latent growth modelling (Chan, 2002) would better serve the needs of talent measurement. There exists no current literature suggesting latent growth modelling as a talent methodology; therefore, this may be an area of potential methodological improvement.

\section{Qualitative assessment}

Talent measurement may be either quantitative or essentially qualitative in nature, or both. In the example mentioned previously, a 'top percentage' identification of managers based on certain criteria such as performance, potential, development scope and age - could be quantitatively measured, left to entirely subjective choice, or both. This is also true for systems in which employees are placed into categories, such as 'rising star' or 'rough diamond' based on certain criteria and with certain TM consequences. As noted by an anonymous referee, it is not uncommon for quantitative systems to provide data to talent committees, who then make final choices based on global impressions that inherently contain subjective choices.

\section{Providers of data}

The performance and potential attributions underlying the grid are typically made by employees' direct supervisors. Hypothetically, this could also be achieved by other means, such as a 360-degree feedback mechanism. However, little evidence exists to suggest that such a practice is common aside from its implementation in performance management.

\section{Combinatorial approach}

To the extent that different foci and criteria for talent exist, a question that has in some respects already been discussed is how one combines the data into a usable system. As discussed, a purely qualitative attribution relies on the mental schema of managers to make attributions regarding talent, which opens up the system to a variety of decisionmaking flaws that have been well documented in the performance appraisal literature, such as halo effects. One particularly damaging issue in this regard which may affect the ability of talent and diversity systems to align is homophily, which may cause managers to rate others similar to themselves as talent, thereby limiting the diversity.
Quantitative combinatory strategies rely on two things. Firstly, the characteristics of input or criteria data (e.g. as seen with the nine-box grid ordinal, categorical inputs can only combine into categorical outputs). Secondly, the mechanisms for combination will profoundly affect the final outcomes (e.g. whether certain criteria or foci are explicitly or implicitly weighted higher than others). For example, do we weight potential higher than performance? Are individuals currently in critical roles given a higher chance of being identified for talent pools? If so, how is this physically done?

This article does not have the space to discuss many of these issues in detail; however, an overarching comment can be made, namely, that such issues are extensively dealt with in the operations research literature (e.g. in the extensive literature on multi-criteria decision analysis [MCDA] or data envelopment analysis [DEA]). It may be a fruitful route to develop TM professionals with operations research training or courses to enable them to approach the mechanisms of data combination for decision purposes more systematically.

\section{Element 3: Final talent choices}

As shown in Figure 1, the pivotal outcome of talent measurement is actual attributions along the lines of broad philosophies regarding talent. The introductory section discussing the definition of talent has already developed the core distinctions between the exclusive approach (developing talent pools in juxtaposition to 'non-talent'), the rarer inclusive approach (at an extreme, seeing all employees as talent and managing each person to their maximum potential) and a hybrid approach that attempts to give some attention to all employees while still identifying specific talent pools.

With regard to talent pools, this seems to be the predominant approach. As a key elaboration, it is sometimes necessary for firms to create different talent pools or segments, for instance, leadership talent pools, international talent pools, technical and/or specialist segments, and so on (Boudreau \& Ramstad, 2005a). Others suggest alternative options such as differentiated talent pools based on predominant individual need (e.g. Uren, 2011).

The notion of talent pools implies differential management and, usually, expenditure. Often, firms enact talent pools because of the belief that specific high-value development opportunities with broad and long-term advancement aims cannot typically be given to everyone as a result of resource constraints, so they will seek to identify individuals under some talent measurement rubric to send on such opportunities. Likewise, specific and costly retention incentives such as retention bonuses may only be targeted to those believed to have long-term value and growth potential within the organisation.

It should be noted that talent measurement does not necessarily obviate movements over time between states by a given individual. As with shorter-term appraisals, just 
because a certain individual is categorised or scored in a certain way (say, as non-top-talent) does not mean that the individual cannot either improve in various inputs to the system (say, performance and potential) or that the organisation re-evaluates its own needs relative to the individual's offering.

A challenge for inclusive TM is whether it implies anything more than good HRM, which, after all, seems to encompass any possible TM intervention and which traditionally has been seen as applied to all employees. Collings and Mellahi (2009) summarise arguments for why inclusive TM may be different. On the measurement front, the point made earlier applies here: talent measurement for inclusive TM must by necessity provide some more complex information than in/out attributions which by definition do not apply to it.

Having settled on a final talent measurement outcome, further considerations that have not been well researched may arise, as discussed next.

\section{Element 4: Further talent measurement considerations}

There exist several further areas of possible uncertainty or controversy within talent measurement. This final section discusses some of these issues, including some that have not been discussed before. Figure 1 lists areas of possible uncertainty or controversy them and differentiates their impact by talent measurement system, although this is a rough allocation.

\section{Should individuals be told about their talent status?}

One area of controversy that has been subjected to some analysis and debate is whether individuals should be told about their talent status or score, especially early in their progression. As indicated in Figure 1, however, this is a factor faced only by organisations using talent pool concepts, notably in the exclusive approach where talent is contrasted implicitly with 'non-talent'.

The advantage of revealing talent status to individuals is that this potentially affords motivation and commitment to those identified in talent pools or higher measurement categories (Gelens, Dries, \& Hofmans, 2013; Swailes \& Blackburn, 2016), creating an enhanced perception of social exchange within the psychological contract (King, 2016). Of course, those identified as 'non-talent' or in lower measurement categories may experience negative reactions such as loss of engagement or withdrawal behaviours (Gelens et al., 2013; Swailes, 2013; Swailes \& Blackburn, 2016), although for others this may act as a spur to improve. In addition, explicit identification as talent creates high exchange expectations, which, if not met, may cause psychological contract breach (King, 2016; Swailes \& Blackburn, 2016).
An alternative to revealing talent 'status' is simply for managers to enact TM strategies appropriate for the measurement of the individual, without discussing the measurement basis. For instance, managers may tell hightalent individuals that they are to be developed in certain ways or offered retention bonuses, inferring talent status without the need for a label, while lower measurement individuals may be given guidance as to where they are performing well and how they may improve, again, however, without the need of unnecessary labels such as 'adequate member' or the like. Either way, recent evidence suggests that it is important to avoid incongruent messages regarding talent status, which ultimately may lead to the risk of psychological contract breach (Sonnenberg, van Zijderveld, \& Brinks, 2014).

\section{The marriage of talent and diversity and/or transformation}

One question that has received little attention is whether talent and diversity management are necessarily easy bedfellows, especially if the latter manifests as pressure to implement short-term transformative targets based on narrow definitions of diversity. South Africa's black economic empowerment and affirmative action legislation presents examples of such regulatory-driven pressures, which especially with respect to management require rapid consideration of race and gender transformation in particular. Such considerations will naturally affect talent identification, notably within leadership and/or succession pools.

The effects of such policy interactions on talent measurement mechanisms are not entirely self-evident. One obvious approach is to engage in excellent diversity attraction, development and retention such that talent pools are naturally stocked with appropriately diverse individuals, in which case measurement can essentially ignore the issues of diversity. However, especially in the context of skills shortages, this strategy may be too long term and uncertain to ensure an appropriate mix of individuals in affected talent pools. Shorter-term, more deliberate mechanisms may be required.

Let us consider a typical South African company which faces transformation pressures to increase percentages of black and female staff in middle to senior management positions in particular, and must primarily achieve this by working with an equivalently staffed talent leadership pool which will be groomed for leadership through mechanisms such as expensive business school courses, mentoring and the like. How does it adjust a traditional talent measurement system to achieve the extra end of transformation? If, say, it used a performance or potential system with no other considerations, it cannot be guaranteed that the system will produce the required profiles of staff.

One option is first to segment the talent pool by quotas of required groups, and then pick the best available performers 
or potentials within each subgroup. However, this may leave top candidates unchosen for the pool, given the need to limit segment sizes. With unlimited resources, the firm could hypothetically expand the talent pool to include all relevant candidates, while still ensuring adequate numbers of desired candidates for ultimate transformation of the management levels; however, such a strategy is prohibitively expensive for more constrained firms and may lead to resentment by those chosen for such a talent pools but who ultimately may find their ability to progress limited by transformation imperatives (e.g. Cappelli, 2008). Another approach may be to redefine the actual measurement bases for this talent pool, perhaps focusing more on potential and specifying potential to have a transformation requirement or weighting (a possibility hinted at by Swailes et al., 2014, p. 531).

One promising area that may help is the addition of an environmental aspect to talent criteria, which has been noted as a potentially key aspect of talent development (Meyers, van Woerkom, \& Dries, 2013). Explicitly building consideration of background environment into talent measurement may provide options for increased diversity. However, no explicit guidelines exist for this in measurement systems, suggesting another area for exploration.

Little has been explicitly discussed on this issue despite transformation and talent forming dual imperatives for organisations in many countries such as South Africa.

\section{Integrating individual and role measurement systems}

This issue has been discussed to some extent in the preceding sections. If role measurement is even included, the question at this stage is whether to integrate individual and role measurement at the measurement stage or to leave them separate but align their information at the TM stage, or in essence both. An example of the former approach is using role information in scoring employees for talent pool membership, for instance, requiring higher performance or potential scores from individuals in non-critical roles than in critical roles. The latter approach is that of Huselid et al. (2005), in which they suggest moving ' $A$ ' talent to ' $\mathrm{A}$ ' positions over time, removing ' $\mathrm{C}$ ' players from 'A' positions, and so on. This really places role measurement in the HR planning realm.

\section{Element 5: Subsequent talent management}

Various suggestions exist for linking such measurement systems to managerial implications. A basic approach word that is commonly referenced (e.g. 'stretch' for the high-performing high-potential 'star performer' group) has already been suggested in Figure 1. Figure 3 adds detail to such suggestions, based on suggestions by sources ranging from the academic to the practitioner (e.g. Caruso, 2012).

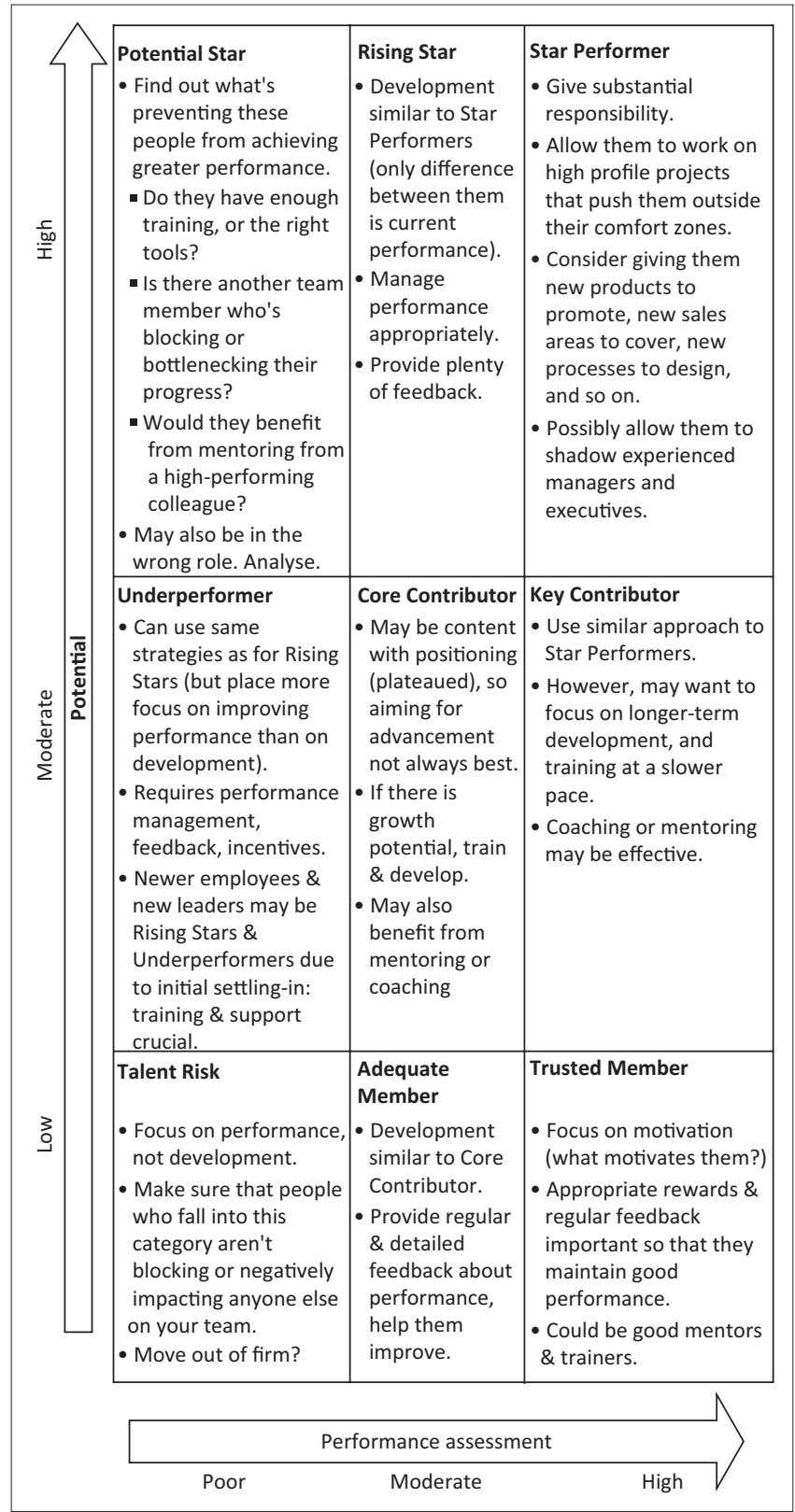

FIGURE 3: Some possible reactions to employees in nine-box grid positions.

In organisations that also work off a 'top talent pool' concept, models such as the nine-box grid can act as an intermediate measurement step, with top talent then identified potentially as consisting only of those in certain of the categories (for instance, an organisation might define 'top talent' as star performers, rising stars and key contributors).

A further issue is whether the broad talent measurement criteria generally used - typified either by general 'top talent pool' allocation or by performance and potential measurement - are helpful to the TM processes that they are meant to initiate. For instance, talent managers may wish to target specific development and training initiatives to individuals, know whether to apply retention options and the like.

Simply being placed in a top talent pool gives no useful individual-level information for TM and would therefore 
have to be supplemented with further analysis, unless organisations are content to apply generic policies to talent. While discrepancies between performance and potential may lead to some differentiation of strategies, as seen earlier with the nine-box grid, these guidelines are still quite general. It is desirable that explicit analysis of individual positioning within TM areas should be done to provide a more direct route for TM. For instance, within training and development, individuals could be scored with regard to the applicability of management development, leadership training or the like. Managers could score individuals on the desirability of retaining for the long term. Such analysis would therefore not only provide the basis for talent differentiation but also give individual-level guidance for subsequent TM.

A final note again supports the use of role analysis: such information supports a great many TM processes from recruitment (with more effort put into critical jobs and aligning talent to them), succession and retention (with, again, more focus on critical positions) and the like.

\section{Implications for research}

Many research agendas arise from this article. Firstly, it would be desirable for research to survey current usage of talent measurement in South African organisations. Furthermore, employee, manager and talent professional views on the success and desirability of various approaches would be desirable (for instance, in exclusive vs. more inclusive systems). One important point arising from the model in Figure 1 is that despite its popularity the purely exclusive approach (especially where initiated through in/out measurement only) has many potential disadvantages, such as being less likely to integrate with transformation imperatives, creating in-out groups and subsequent tensions, and being less likely to facilitate subsequent TM with quality information. Having said this, managers may prefer the capacity of exclusive TM to focus budgets and effort sharply, rather than attempt to split the attention of TM initiatives. Given these tensions, in South Africa particularly, methods for integrating diversity and TM should be surfaced in case studies and should be disseminated. Controversial areas such as whether to reveal talent status in South Africa should also be studied, with one possibility being experimental approaches.

\section{Conclusion}

Talent measurement has become pervasive as part of TM, but has remained relatively poorly discussed. This article has provided a holistic framework for talent measurement, rooted the practice in management theory, reviewed common usage and suggested several areas of research and possible consideration as organisations seek to enhance their analysis and deployment of talent.

\section{Acknowledgements}

This work is based on the research supported by the National Research Foundation of South Africa (grant number 103588).

\section{Competing interests}

The author declares that he has no financial or personal relationships that may have inappropriately influenced him in writing this article.

\section{References}

Akerlof, G. (1976). The economics of caste and of the rat race and other woeful tales. The Quarterly Journal of Economics, 90(4), 599-617. https://doi.org/ $10.2307 / 1885324$

Barney, J.B. (1991). Firm resources and sustained competitive advantage. Journal of Management, 17, 99-120. https://doi.org/10.1177/014920639101700108

Barney, J.B., \& Wright, P.M. (1998). On becoming a strategic partner: The role of human resources in gaining competitive advantage. Human Resource Management, 37(1), 31-46. https://doi.org/10.1002/(SICI)1099-050X(199821)37:1<31::AID-HRM4> 3.0.CO; $2-W$

Boudreau, J.W. (2013). Appreciating and 'retooling' diversity in talent management conceptual models: A commentary on "The psychology of talent management: A review and research agenda." Human Resource Management Review, 23, 286289. https://doi.org/10.1016/j.hrmr.2013.08.001

Boudreau, J.W., \& Ramstad, P.M. (2005a). Talentship and the new paradigm for human resource management: From professional practices to strategic talent decision science. Human Resource Management Planning, 28(2), 17-26.

Boudreau, J.W., \& Ramstad, P.M. (2005b). Talentship, talent segmentation, and sustainability: A new HR decision science paradigm for a new strategy definition. Human Resource Management, 44(2), 129-136. https://doi.org/10.1002/ hrm.20054

Boxall, P.F. (1996). The Strategic HRM debate and the resource-based view of the firm Human Resource Management Journal, 6(3), 59-75. https://doi.org/10.1111/ j.1748-8583.1996.tb00412.x

Cappelli, P. (2008). Talent management for the twenty-first century. Harvard Business Review, 86(3), 74-81.

Caruso, K. (2012, April 12). Development at the Top - Use the 9 Box to Develop Talent in Succession Planning. Via People Discover the Talent Within. Retrieved from http://web.viapeople.com/viaPeople-blog/bid/81566/Development-at-the-TopUse-the-9-Box-to-Develop-Talent-in-Succession-Planning

Chan, D. (2002). Latent growth modeling. In F. Drasgow \& N. Schmitt (Eds.), The Jossey-Bass business \& management series. Measuring and analyzing behavior in organizations: Advances in measurement and data analysis (pp. 302-349). San organizations: Advances in
Francisco, CA: Jossey-Bass.

CIPD. (2009). Talent management: Factsheet. London: CIPD.

CIPD. (2016). Talent management overview: Factsheet. Talent Management Overview: Factsheet. Retrieved from https://www.cipd.co.uk/knowledge/ strategy/resourcing/talent-factsheet

Collings, D.G., \& Mellahi, K. (2009). Strategic talent management: A review and research agenda. Human Resource Management Review, 19(4), 304-313. https:// doi.org/10.1016/j.hrmr.2009.04.001

Gallardo-Gallardo, E., Dries, N., \& González-Cruz, T.F. (2013). What is the meaning of 'talent' in the world of work? Human Resource Management Review, 23, 290300. https://doi.org/10.1016/j.hrmr.2013.05.002

Gelens, J., Dries, N., \& Hofmans, J. (2013). The role of perceived organizational justice in shaping the outcomes of talent management: A research agenda. Human Resource Management Review, 23, 341-353. https://doi.org/10.1016/j.hrmr. 2013.05.005

Greenwald, B.C. (1986). Adverse selection in the labour market. The Review of Economic Studies, 53(3), 325-347. https://doi.org/10.2307/2297632

Huselid, M., Beatty, R., \& Becker, B. (2005). 'A' players or 'A' positions? The strategic logic of workforce management. Harvard Business Review, 83(12), 110-117.

Iles, P. (2008). Talent balancing: Staffing your company for long-term success. Human Resource Development International, 11(2), 215-218. https://doi.org/10.1080/ 13678860801933020

Iles, P., Chuai, X., \& Preece, D. (2010). Talent management and HRM in multinational companies in Beijing: Definitions, differences and drivers. Journal of World Business, 45(2), 179-189. https://doi.org/10.1016/j.jwb.2009.09.014

lles, P., \& Preece, D. (2006). Developing leaders or developing leadership? The Academy of Chief Executives' programmes in the North East of England. Leadership, 2(3), 317-340. https://doi.org/10.1177/1742715006066024

Kahn, L.B. (2013). Asymmetric information between employers. American Economic Journal: Applied Economics, 5(4), 165-205. https://doi.org/10.1257/app.5.4.165

Kang, S.C., Morris, S.S., \& Snell, S.A. (2007). Relational archetypes, organizational learning and value creation: Extending the human resource architecture. Academy of Management Review, 32(1), 236-256. https://doi.org/10.5465/ AMR.2007.23464060

King, K.A. (2016). The talent deal and journey: Understanding how employees respond to talent identification over time. Employee Relations, 38(1), 94-111. https://doi. org/10.1108/ER-07-2015-0155

Kristof-Brown, A.L., Zimmerman, R.D., \& Johnson, E.C. (2005). Consequences of individuals' fit at work: A meta-analysis of person-job, person-organization, person-group, and person-supervisor fit. Personnel Psychology, 58(2), 281-342. https://doi.org/10.1111/j.1744-6570.2005.00672.x 
Kulkarni, S.P., \& Ramamoorthy, N. (2005). Commitment, flexibility and the choice of employment contracts. Human Relations, 58(6), 741-761. https://doi.org/ employment contracts. Hum

Lado, A.A., \& Wilson, M.C. (1994). Human resource systems and sustained competitive advantage: A competency-based perspective. Academy of Management Review, 19(4), 699-727.

Landers, R.M., Rebitzer, J.B., \& Taylor, L.J. (1996). Rat race redux: Adverse selection in the determination of work hours in law firms. The American Economic Review, 86(3), 329-348.

Lepak, D.P., \& Snell, S.A. (1999). The human resource architecture: Toward a theory of human capital allocation and development. Academy of Management Review, 24(1), 31-48.

Lepak, D.P., \& Snell, S.A. (2002). Examining the human resource architecture: The relationships among human capital, employment, and human resource configurations. Journal of Management, 28(4), 517-543. https://doi.org/10.1177/ 014920630202800403

Lewis, R.E., \& Heckman, R.J. (2006). Talent management: A critical review. Human Resource Management Review, 16(2), 139-154. https://doi.org/10.1016/j. hrmr.2006.03.001

Liu, W., Lepak, D.P., Takeuchi, R., \& Sims, H.P. (2003). Matching leadership styles with employment modes: Strategic human resource management perspective. Human Resource Management Review, 13(1), 127-152. https://doi.org/10.1016/S1053 4822(02)00102-X

Martin, G. (2009). Driving corporate reputations from the inside: A strategic role and strategic dilemmas for HR? Asia Pacific Journal of Human Resources, 47(2), strategic dilemmas for HR? Asia Pacific Journal of
219-235. https://doi.org/10.1177/1038411109105443

McCarthy, D. (2009). How to 'Score' Leadership Potential When Using the Performance and Potential Matrix. Retrieved from http://www.greatleadershipbydan. com/2009/02/how-to-score-leadership-potential-when.html

Meyers, M.C., van Woerkom, M., \& Dries, N. (2013). Talent - Innate or acquired? Theoretical considerations and their implications for talent management. Human Resource Management Review, 2(4), 305-321. https://doi.org/10.1016/j. hrmr.2013.05.003

Minbaeva, D., \& Collings, D.G. (2013). Seven myths of global talent management. The International Journal of Human Resource Management, 24(9), 1762-1776. https://doi.org/10.1080/09585192.2013.777539

Nijs, S., Gallardo-Gallardo, E., Dries, N., \& Sels, L. (2014). A multidisciplinary review into the definition, operationalization, and measurement of talent. Journal of World Business, 49(2), 180-191. https://doi.org/10.1016/j.jwb.2013.11.002
Palthe, J., \& Kossek, E.E. (2003). Subcultures and employment modes: Translating HR strategy into practice. Journal of Organizational Change Management, 16(3), 287-308. https://doi.org/10.1108/09534810310475532

Schneider, B. (1987). The people make the place. Personnel Psychology, 40(3), 437-453. https://doi.org/10.1111/j.1744-6570.1987.tb00609.x

Silzer, R., \& Church, A.H. (2009). The pearls and perils of identifying potential. Industrial and Organizational Psychology, 2, 377-412. https://doi.org/10.1111/ j.1754-9434.2009.01163.x

Sonnenberg, M., van Zijderveld, V., \& Brinks, M. (2014). The role of talent-perception incongruence in effective talent management. Journal of World Business, 49(2), 272-280. https://doi.org/10.1016/j.jwb.2013.11.011

Swailes, S. (2013). The ethics of talent management. Business Ethics: A European Review, 22(1), 32-46. https://doi.org/10.1111/beer.12007

Swailes, S., \& Blackburn, M. (2016). Employee reactions to talent pool membership. Employee Relations, 38(1), 112-128. https://doi.org/10.1108/ ER-02-2015-0030

Swailes, S., Downes, Y., \& Orr, K. (2014). Conceptualising inclusive talent management: Potential, possibilities and practicalities. Human Resource Development International, 17(5), 529-544. https://doi.org/10.1080/13678868.2014.954188

Tansley, C. (2011). What do we mean by the term "talent" in talent management? Industrial and Commercial Training, 43(5), 266-274. https://doi.org/10.1108/ 00197851111145853

Ulrich, D., \& Smallwood, N. (2012). What is Talent? Leader to Leader, Winter, 55-61. https://doi.org/10.1002/ltl.20011

Uren, L. (2011). What talent wants: The journey to talent segmentation. Strategic HR Review, 10(6), 31-37. https://doi.org/10.1108/14754391111172805

Wernerfelt, B. (1984). A resource-based view of the firm. Strategic Management Journal, 5, 171-180. https://doi.org/10.1002/smj.4250050207

Wright, P.M., Dunford, B.B., \& Snell, S.A. (2001). Human resources and the resource based view of the firm. Journal of Management, 27(6), 701-721. https://doi. org/10.1177/014920630102700607

Wright, P.M., \& McMahan, G.C. (1992). Theoretical perspective for strategic human resource management. Journal of Management, 18(2), 295-320. https://doi. org/10.1177/014920639201800205

Wright, P.M., McMahan, G.C., \& McWilliams, A. (1994). Human resources and sustained competitive advantage: A resource-based perspective. International Journal of Human Resource Management, 5, 301-326. https://doi.org/10.1080/ 09585199400000020 